\title{
PRINSIP - PRINSIP DAN STANDAR DOKUMENTASI DALAM KEPERAWATAN
}

\author{
Friderikus Zebua
}

zebuafriderikus@gmail.com

\section{LATAR BELAKANG}

Dokumentasi keperawatan menjadi salah satu fungsi yang paling penting dari perawat sejak zaman Florence Nightingale, sistem pelayanan kesehatan mengharuskan adanya pendokumentasian karena dapat menjamin kelangsungan perawatan, dapat berfungsi sebagai bukti hukum dari proses perawatan dan mendukung evaluasi kualitas perawatan pasien, perawat yang kurang patuh dalam pendokumentasi asuhan keperawatan akan berakibat pada rendahnya mutu kelengkapan dokumentasi asuhan keperawatan. Departemen kesehatan RI menetapkan capaian standar asuhan keperawatan (SAK) yaitu sebesar 90\% (Depkes RI, 2010, Cheevakasemsook, 2006).

Kemampuan seorang perawat memberikan pelayanan yang baik serta kemudian dapat secara efektif mengkomunikasikan tentang perawatan pasien tergantung pada seberapa baik kualitas informasi yang diberikan serta dokumentasi yang disediakan untuk dimanfaatkan oleh semua profesional kesehatan dan antar bidang pelayanan kesehatan oleh sebab itu kita harus mengetahui bagimana standart dokumentasi keperawatan tersebut, yang dimana dokumentasi keperawatan merupakan aspek yang sangat penting dalam praktik keperawatan, menggambarkan catatan kesehatan klien dan dijadikan alat komunikasi dengan tenaga kesehatan lainnya, sebagimana yang kita ketahui bahwa perawat mempunyai waktu operan dari pagi,siang dan malam jika dokumentasi yang dituliskan salah atau tidak benar maka komunikasi yang diterimapun salah dan akan berdampak buruk bagi kemajuan kesehatan klien.

Pendokumentasian asuhan keperawatan yang tidak dilakukan dengan lengkap dapat menurunkan mutu pelayanan keperawatan karena tidak dapat menilai sejauh mana tingkat keberhasilan asuhan keperawatan yang telah diberikan (Yanti dan Warsito, 2013) Pendokumentasian asuhan keperawatan dilakukan sebagai bukti tindakan keperawatan sudah dilakukan secara professional dan legal sehingga dapat memberikan perlindungan pada perawat dan pasien (Iyer \& Camp, 2005). Pendokumentasian berguna bagi rumah sakit dalam meningkatkan standar akreditasi, sebagai alat komunikasi antar profesi, 
indikator pelayanan mutu, bukti tanggung jawab, dan tanggung gugat perawat, sumber data dan sebagai sarana penelitian (Teytelman, 2002; Jefferies, Johnson, Nicholls \& Lad, 2012).

\section{METODE}

Metode ini menggunakan metode kuantitatif atau pengumpulan data. Berdasarkan dari penjelasan yang didapat dari sumber dan referensi terkait Prinsip - prinsip dan standar dokumentasi keperawatan dalam asuhan keperawatan. Sumber dan Referensi yang di gunakan adalah berupa Journal nasional dan internasional yang di review.

\section{HASIL}

Perawat dapat menyadari bahwa setiap tindakan yang mereka lakukan harus dipertanggungjawabkan dengan melakukan pendokumentasian keperawatan sehingga pelaksanaan asuhan keperawatan dapat berjalan dengan baik. Saat ini diindonesia masih banyak perawat yang belum memberikan pelayanan keperawatan sesuai dengan standar asuhan keperawatan karena tidak disertai dengan pendokumentasian yang lengkap. Maryadi (2007) menyatakan bahwa 65\% perawat kurang memperhatikan standar dokumentasi keperawatan dan lebih memperhatikan asuhan keperawatan kepada pasien secara langsung.

Menurut Potter \& Perry (2010), dokumentasi keperawatan harus mencantumkan seluruh proses asuhan keperawatan, mulai dari pengkajian dengan menetapkan data dasar seorang klien , diagnosa keperawatan untuk mengidentifikasi permasalahan yang dihadapi pasien, intervensi yaitu merencanakan asuhan keperawatan kepada pasien, implementasi yaitu serangkaian kegiatan yang dilakukan oleh perawat untuk membantu klien dari masalah status kesehatan yang dihadapi ke status kesehatan yang lebih baik yang menggambarkan kriteria hasil yang diharapkan dan evaluasi merupakan perbandingan yang sistematik dan terencana tentang kesehatan klien dengan tujuan yang telah ditetapkan, dilakukan berkesinambungan dengan melibatkan klien dan tenaga kesehatan lainnya.

Salah satu upaya untuk meningkatkan kualitas pelayanan adalah dengan melaksanakan standar dokumentasi keperawatan sehingga pelayanan keperawatan pada pasien yang sakit dapat dilaksanakan secara berkelanjutan dan efisiensi waktu dapat dicapai. Upaya untuk meningkatkan kualitas dari pelaksanaan dokumentasi keperawatan adalah dengan melaksanakan audit dokumentasi. Audit dokumentasi dilakukan dengan cara membandingkan pendokumentasian yang ditemukan dalam rekam medik pasien dengan standar pendokumentasian yang ditentukan dalam standar asuhan keperawatan. Aspek yang dinilai dalam pendokumentasian ini adalah pengkajian keperawatan, diagnosa keperawatan, 
perencanaan keperawatan, tindakan keperawatan, evaluasai keperawatan dan catatan asuhan keperawatan. Jadi kualitaskinerja perawat pelaksana dapat dievaluasi melalui audit dokumentasi (Depkes, 2002).

\section{PEMBAHASAN}

\section{A. Prinsip Dokumentasi Keperawatan}

Dokumentasi asuhan keperawatan merupakan tuntutan profesi yang harus dapat dipertanggung jawabkan, baik dari aspek etik maupun aspek hukum. Artinya dokumentasi asuhan keperawatan yang dapat dipertanggungjawabkan dari kedua aspek ini berkaitan erat dengan aspek manajerial, yang disatu sisi melindungi pasien sebagai penerima pelayanan (konsumen) dan disisi lain melindungi perawat sebagai pemberi jasa pelayanan dan asuhan keperawatan (Hidayat, 2008). Nursalam (2011) menerangkan bahwa dokumentasi keperawatan mempunya makna yang penting dilihat dari berbagai aspek seperti aspek hukum, kualitas pelayanan, komunikasi, keuangan, pendidikan, penelitian, dan akreditasi. Pengisian dokumentasi keperawatan yang tidak memenuhi standar dapat berakibat pada terjadinya kesalahan diagnosa dan pemberian tindakan yang tidak tepat kepada pasien. Selain itu dokumentasi keperawatan merupakan bukti hukum yang dapat dipergunakan untuk mendukung perawat ketika menghadapi permasalahan hukum.

Dokumentasi keperawatan adalah suatu catatan yang memuat seluruh data yang dibutuhkan untuk menentukan diagnosis keperawatan, perencanaan keperawatan, tindakan keperawatan, dan penilaian keperawatan yang disusun secara sistematis, valid, dan dapat dipertanggungjawabkan secara moral dan hukum (Ali, 2009).Menurut Asmadi (2008) dokumentasi merupakan pernyataan tentang kejadian atau aktifitas yang otentik dengan membuat catatan tertulis. Dokumentasi keperawatan berisi hasil aktivitas keperawatan yang dilakukan perawat terhadap klien, mulai dari pengkajian hingga evaluasi.

Berdasarkan penjelasan Ali (2010) menjelaskan tujuan dokumentasi asuhan keperawatan keperawatan yaitu :

- Menghindari kesalahan, tumpang tindih, dan ketidaklengkapan informasi dalam asuhan keperawatan.

- Terbinanya koordinasi yang baik dan dinamis antara sesama atau dengan pihak lain melalui dokumentasi keperawatan yang efektif.

- Meningkatkan efisiensi dan efektivitas tenaga keperawatan. 
- Terjaminnya kualitas asuhan keperawatan.

- Tersedianya perawat dari suatu keadaan yang memerlukan penanganan secara hukum.

- Tersedianya data-data dalam penyelenggaraan penelitian karya ilmiah, pendidikan,dan penyusun/penyempurnaan standar asuhan keperawatan.

- Melindungi klien dari tindakan malpraktek.

Pendokumentasian yang tidak lengkap akan memberikan kerugian bagi klien karena informasi penting terkait perawatan dan kondisi kesehatannya terabaikan (Teytelman, 2002). Braaf, Manias dan Riley (2011) menjelaskan bahwa pendokumentasian yang tidak efisien dan tidak efektif akibat dari kualitas dan keakuratannya kurang memadai menyebabkanterjadinya kesalahan komunikasi antar perawat maupun profesi lain. Komisi keselamatan perawatan dan kualitas kesehatan Australia pada 2008 mengidentifikasi 13\% dari kesalahan manajemen klinis berasal dari kesalahan dokumentasi (Jefferies, Johnson, Nicholls \& Lad, 2012).

Ada beberapa manfaat proses keperawatan menurut Ali (2009), Proses keperawatan bermanfaat bagi klien, perawat, institusi pelayanan, danmasyarakat (lingkungan).

1) Manfaat bagi Klien Klien mendapatkan pelayanan keperawatan yang berkualitas, efektif, dan efisien. Asuhan keperawatan yang diberikan telah diseleksi sesuai dengan kebutuhan klien melalui penelusuran data, rumusan permasalahan yang matang, diagnosis keperawatan yangtepat, rencana.yang terarah, tindakan yang sesuai dengan rencana, dan penilian yang terus?menerus.

2) Manfaat bagi tenaga keperawatan Proses keperawatan akan meningkatkan kemandirian tenaga keperawatan dan pelaksanaan asuhan keperawatan dan tidakbergantung pada profesi lain. Proses ini juga memberi kepuasan yang optimal bagi tenaga keperawatan yang berhasil dalam pelaksanaan asuhan keperawatannya.

3) Manfaat bagi Institusi Institusi pelayanan akan merasakan manfaat, antara lainklien merasa puas, cepat sembuh, pelayanan yang bermutu sekaligus merupakan promosi institusi tersebut. Dengan demikian, klien meningkat dan keuntungan pun meningkat dan Citra institusi bertambah baik di mata masyarakat.

\section{B. Standar Dokumentasi Keprawatan}

Standar dokumentasi adalah pernyataan tentang kualitas dan kuantitas dokumentasi dipertimbangkan secara baik untuk memperkuat pola pencatatan dan sebagai petunjuk atau pedoman 
pendokumentasian dalam tindakan keperawatan. Perawat memerlukan standar dokumentasi sebagai petunjuk dan arah agar tidak terjadi penyimpangan dan melakukan teknik pencatatan dengan benar.(Yustiana \& Abdul,2016).standar dokumentasi sangat penting dalam penyusunan dokumentasi asuhan keperawatan agar tidak terjadi kesalahan dalam pemberian informasi kemajuan kesehatan klien kepada petugas kesehatan lainnya .

Setelah memberikan asuhan keperawatan kepada klien dan keluarga, dokumentasi merupakan bagian yang tidak bisa di pisahkan, terutama dalam pencapaian mutu kualitas pelayanan asuhan keperawatan. Setiap pelaksanaan tugas dalam keperawatan, harus ada bukti yang tercatat dan nantinya bila ada sesuatu yang terjadi bisa ditelusuri semenjak awal dari dokumentasi keperawatan yang telah dibuat serta dapat menjadi bukti hukum apabila terjadi hal hal yang tidak diinginkan juga merupakan perlindungan hukum bagi perawat. Ketika seorang perawat akan menuliskan dokumentasi yang efektif perawat harus mengikuti kaidah kaidah sebagai berikut agar dipahami oleh petugas kesehatan lainnya:

a. Simplicity: menggunakan kata-kata dasar, sederhana dan mudah dipahami. Oleh petugas kesehatan lainnya

b. Conservatism: setiap pendokumentasian kesimpulan diagnosa keperawatan harus akurat, didasarkan pada informasi yang terkumpul baik secara subjektif atau objektif.

c. Ptience: mempergunakan waktu yang cukup untuk mengetahui apa yang terjadi pada pasien dan apa yang dilakukan pasien.

d. Irrefutability: pendokumentasian harus yang jelas dan obyektif dengan penulisan yang dapat dibaca. Menurut Yustiana \& Abdul tahun 2016 standar dokumentasi yang lengkap menunjukkan tiga komponen dimana setiap komponen disertai indikator.

Komponen standar dokumentasi terdiri dari Komunikasi, Akuntabilitas dan Kewajiban, Keamanan.

Standar 1: Komunikasi

Perawat melakukan dokumentasi yang berisi informasi yang akurat, relevan dan komprehensif mengenai kondisi klien, kebutuhan klien, intervensi keperawatan dan hasil kesehatan klien. Indikator Perawat

a. Memberikan tanda tangan lengkap atau inisial, dan gelar profesional dengan semua dokumentasi;

b. Memberikan tanda tangan lengkap, dan inisial pada data base saat initialling dokumentasi; 
c. Memastikan bahwa dokumentasi tulisan tangan terbaca dan menggunakan tinta permanen;

d. Menggunakan singkatan dan simbol yang masing-masing singkatan dan simbol tersebut memiliki interpretasi berbeda dantelah disepakati dan diterima dalam bidang pelayanan dan profesi kesehatan;

e. Mendokumentasikan saran, perawatan atau layanan yang diberikan kepada individu dalam kelompok, kelompok khusus, komunitas atau populasi (misalnya: sesi pendidikan kelompok);

f. Mendokumentasikan asuhan keperawatan yang diberikan teknologi informasi dan telekomunikasi (misalnya: memberikan terapi melalui telepon)

g. Mendokumentasikan inform consent ketika perawat memberikan pengobatan atau intervensi tertentu dan advokasi kebijakan dokumentasi yang jelas dan prosedur yang konsisten dengan Standar Asuhan Keperawatan (SAK). Seorang perawat dapat memenuhi standar dokumentasi keperawatan dengan cara:

- Memastikan dokumentasi yang merupakan catatan lengkap tentang asuhan keperawatan tersedia dan mencerminkan semua aspek proses keperawatan, termasuk penilaian, perencanaan, intervensi (independen dan kolaboratif) dan evaluasi;

- Mendokumentasikan informasi baik berupa data objektif maupun data subjektif;

- Memastikan bahwa rencana perawatan jelas, terkini, relevan dan individual untuk memenuhi kebutuhan dan keinginan klien;

- Meminimalkan duplikasi informasi dalam catatan kesehatan;

- Mendokumentasikan komunikasi yang signifikan dengan anggota keluarga/orang lain yang signifikan, pengganti pengambil keputusan dan penyedia perawatan lainnya,

- Memastikan bahwa data informasi perawatan klien telah disimpan dalam dokumen hard copy sementara (seperti KARDEX, laporan shift atau buku komunikasi) serta disimpan dalam catatan kesehatan permanen.

Standar 2: Akuntabilitas dan Kewajib

Perawat mendokumentasikan asuhan keperawatan sesuai dengan standar profesional dan etika, peraturan dan kebijakan yang relevan dari rumah sakit. Indikator Perawat:

a. Pendokumentasian perawatan dilakukan sesegara mungkin setelah tindakan perawatan dilakukan.

b. Penulisan tanggal dan waktu pelaksanaan tindakan perawatan.

c. Dokumentasi di buat berdasarkan urutan kronologis kejadian.

d. Pendokumentasian tidak boleh meninggalkan baris kosong pada lembar dokumentasi perawat harus 
menutup bagian yang kosong itu dengan garis yang memenuhi lembar dokumentasi.Bilamana dokumentasi menggunakan sistem elektronik perawat harus menahan diri sampai koreksi entri data yang keliru sambil memastikan bahwa informasi asli tetap terlihat sesuai dengan kebijakan aturan rumah sakit.

e. Mengoreksi entri data yang keliru sambil memastikan bahwa informasi asli.tetap terlihat.

f. Dilarang menghapus, mengubah atau memodifikasi.dokumentasi orang lain

g. Dokumen apapun yang tak terduga, kejadian tak terduga atau abnormal untuk klien, harus di rekam berdasarkan fakta kejadian dengan berkaiatan dengan proses perawatan.

\section{Standar 3: Keamanan}

Perawat melindungi informasi kesehatan klien dengan menjaga kerahasiaan dan menyimpan informasi sesuai dengan prosedur yang konsisten sesuai dengan standar profesional dan etika berdasarkan peraturan perundang-undangan yang relevan. Indikator Perawat :

a. Memastikan bahwa informasi perawatan klien yang relevan diambil dalam catatan kesehatan klien, seperti yang didefinisikan oleh kebijakan rumah sakit.

b. Mempertahankan kerahasiaan informasi kesehatan klien, termasuk password atau informasi yang diperlukan untuk mengakses catatan kesehatan klien.

c. Memahami dan mematuhi kebijakan, standar dan peraturan perundangundangan yang berkaitan dengan kerahasiaan, privasi dan keamanan.

d. Mengakses informasi hanya dapat dilakukan oleh perawat yang memiliki kebutuhan profesional untuk memberikan perawatan.

e. Menjaga kerahasiaan klien lain dengan menggunakan inisial atau kode ketika mengacu pada klien lain dalam catatan kesehatan klien (misalnya, menggunakan inisial ketika mengutip teman sekamar klien)

f. Memfasilitasi hak-hak klien untuk mengakses informasi kesehatan tentang dirinya.

g. Memeriksa dan mendapatkan salinan catatan kesehatan, seperti yang didefinisikan oleh kebijakan rumah sakit. 
h. Memperoleh persetujuan dari klien atau pengganti pengambil keputusan untuk menggunakan dan mengungkapkan informasi kepada orang lain di luar lingkaran perawatan, sesuai dengan peraturan yang relevan.

i. Menggunakan metode yang aman untuk mengirimkan informasi kesehatan klien (misalnya, menggunakan garis aman untuk fax atau e-mail).

j. Mempertahankan catatan kesehatansesuai dengan kebijakan dan peraturan

organisasi dan melakukannya sebagai bagian dari tanggungjawab perawat.

k. Memastikan penghancuran dokumen yang sudah tidak diperlukan dengan aman dan menjaga rahasia dokumen tetap terjaga.

\section{PENUTUP}

\section{Simpulan}

Dokumentasi asuhan keperawatan yang dapat dipertanggungjawabkan dari kedua aspek ini berkaitan erat dengan aspek manajerial, yang disatu sisi melindungi pasien sebagai penerima pelayanan (konsumen) dan disisi lain melindungi perawat sebagai pemberi jasa pelayanan dan asuhan keperawatan.

Standar dokumentasi adalah pernyataan tentang kualitas dan kuantitas dokumentasi dipertimbangkan secara baik untuk memperkuat pola pencatatan dan sebagai petunjuk atau pedoman pendokumentasian dalam tindakan keperawatan. Perawat memerlukan standar dokumentasi sebagai petunjuk dan arah agar tidak terjadi penyimpangan dan melakukan teknik pencatatan dengan benar, standart dokumentasi sangat penting dalam penyusunan dokumentas asuhan keperawatan agar tidak terjadi kesalahan dalam pemberian informasi kemajuan kesehatan klien kepada petugas kesehatan lainnya

\section{DAFTAR PUSTAKA}

Ali, (2010). Konsep dukungan keluarga. Jakarta: salemba medika

Budiono. (2016). Konsep Dasar Keperawatan. Jakarta: Kementerian Kesehatan Republik Indonesia.

Kosim, Y. (2015). Konsep Dasar Keperawatan. Jakarta : Cv. Trans Info Medika. 
Kozier dkk. (2010). Fundamental Keperawatan Konsep, Proses, dan Praktik Edisi 7 Volume 2. Jakarta : EGC.

Kozier dkk. (2015). Buku Ajar Fundamental Keperawatan,Konsep, Proses,dan Praktik Volume 7. Jakarta : EGC.

Muttaqin, A. (2010). Pengkajian Keperawatan Aplikasi pada Praktik Klinik. Jakarta : Salemba Medika

Simamora, R. H., Purba, J. M., Bukit, E. K., \& Nurbaiti, N. (2019). Penguatan Peran Perawat Dalam Pelaksanaan Asuhan Keperawatan Melalui Pelatihan Layanan Prima. JPPM (Jurnal Pengabdian Dan Pemberdayaan Masyarakat), 3(1), 25-31.

Ulpa, D. 2012. Keperawatan Klinis. Jurnal Keperawatan Klinis 2 (1)

Wardani, I. Y. 2012. Dukungan Keluarga: Factor Penyebab Ketidak Patuhan Klien Menjalani Pengobatan. Jurnal Keperawatan Indonesia 15 (1)

Wariyanti AS. (2014). Hubungan antara Kelengkapan Informasi Medis Dengan Keakuratan Kode Diagnosis pada Dokumen Rekam Medis Rawat Ilmu Kesehatan Un

Yustiana \& Abdul. (2016). Dokumentasi Keperawatan.Jakarta.Kementrian kesehatan Republik Indonesia. 